\title{
O que fazer com o que a escola faz com meu corpo? Táticas de estudantes à luz de Michel de Certeau
}

\section{Resumo}

Eanes dos Santos Correia

Veleida Anahi da Silva

Universidade Federal de Sergipe

Willdson Robson Silva do Nascimento

Universidade Estadual Paulista "Júlio de Mesquita Filho"

Este trabalho tem o objetivo de compreender o uso da bricolagem por estudantes adolescentes de duas escolas públicas do interior do Estado de Sergipe como forma de resistência sobre o controle dos seus corpos, instituídos no seu dia a dia e pela escola. Tentamos discutir e analisar os dados à luz de Michel de Certeau com base nos conceitos de táticas e estratégias, destacando as táticas que são possíveis práticas que os estudantes adotam para se desviar das lógicas da escola que os disciplinam e tentar regular seus corpos. Utilizamos, como instrumento de coleta de dados deste estudo, a entrevista de grupo com vinte e um estudantes do oitavo ano do ensino fundamental com faixa etária entre doze e dezesseis anos. Verificamos que as atitudes cotidianas dos estudantes são permeadas de ações que podem usar de bricolagens como táticas de vivências dentro e fora do ambiente escolar. Com base na posição subjetiva dos estudantes diante das estratégias da escola, a maioria se mostra subversiva e bricolante.

Palavras-chave: Corpo. Estudantes adolescentes. Escola. Táticas.

\section{What to do with what school does to my body? Tactics of stu- dents in the light of Michel de Certeau}

\section{Abstract}

This paper aims to understand the use of bricolage (do-it-yourself) by teenage students from two public schools in the countryside of the State of Sergipe as a form of resistance on the control of their bodies, instituted by the school in their daily life. We try to discuss and analyze the data in the light of Michel de Certeau based on the concepts of tactics and strategies, highlighting the tactics that are possible practices that students adopt to deviate from the school logic that disciplines them and try to regulate their bodies. We used, as a data collection instrument of this study, the group interview with twenty one students of the eighth year of elementary school with a age range between twelve and sixteen years. We verified that the daily attitudes of the students are permeated by actions that can use bricolage as tactics of experiences inside and outside the school environment. Based on the subjective position of the students in front of the strategies of the school, the majority is subversive and bricolating.

Keywords: Body. Adolescent students. School. Tactics. 


\section{¿Qué hacer con lo que la escuela hace con mi cuerpo? Tácticas de estudiantes a la luz de Michel de Certeau}

\section{Resumen}

Este trabajo tiene el objetivo de comprender el uso del trabajo artesanal por estudiantes adolescentes de dos escuelas públicas del interior del Estado de Sergipe como forma de resistencia sobre el control de sus cuerpos, instituidos en su día a día y por la escuela. Intentamos discutir y analizar los datos a la luz de Michel de Certeau con base en los conceptos de tácticas y estrategias, destacando las tácticas que son posibles prácticas que los estudiantes adoptan para desviarse de las lógicas de la escuela que los disciplinan e intentar regular sus cuerpos. Utilizamos, como instrumento de recolección de datos de este estudio, la entrevista de grupo con veintiún estudiantes de octavo año de la enseñanza fundamental con franja etaria entre doce y dieciséis años. Verificamos que las actitudes cotidianas de los estudiantes están permeadas de acciones que pueden usar trabajos artesanales como tácticas de vivencias dentro y fuera del ambiente escolar. Con base en la posición subjetiva de los estudiantes ante las estrategias de la escuela, la mayoría se muestra subversiva y artesanal.

Palabras clave: Cuerpo. Estudiantes adolescentes. Escuela. Tácticas.

\section{Introdução}

"Controle-se! Sente-se corretamente! Pare de conversar, pois você está na sala de aula! Sala de aula não é lugar de bagunça, é lugar de estudo!" Toda ou qualquer pessoa, seja ela professor ou aluno, já ouviu ou falou este tipo de comentário na escola. Constantemente, adolescentes e crianças são corrigidos e disciplinados por todos os lados em casa, na rua, na escola, no clube, no parque e entre seus familiares.

A disciplina e o controle do corpo na escola têm sua origem na educação jesuíta e não é um fenômeno recente da nossa sociedade contemporânea. Para Charlot, na pedagogia tradicional jesuíta no que se refere ao corpo:

Essa é a educação: um combate contra a natureza, para tirar a alma da criança fora da corrupção. $\bigcirc$ desejo, o corpo: esses são os inimigos do pedagogo tradicional. Sendo assim, a educação deve ser, antes de tudo, inculcação de normas e aprendizagem de regras. Base de toda educação escolar: aprender a ficar sentado sem se mexer, durante bastante tempo, ou seja, aprender a domar o corpo, a sua espontaneidade, os seus desejos. A seguir, ensinam-se disciplinas, isto é, conjuntos de saberes sistematizados cujo primeiro objetivo é disciplinar a criança (CHARLOT, 2013, p. 191). 
corpo torna-se um canal pelo qual o homem transgride e se corrompe, devendo ser disciplinado, assim pensava a educação escolar desde seus primórdios no pensamento cristão na educação jesuíta. Esse tipo de controle tem se capilarizado dentro de todos os ambientes educacionais. Nessa perspectiva, o poder disciplinar precisa agir sobre cada um dos corpos (FOUCAULT, 2004). Desta forma, precisamos confirmar, então, esses corpos nas instituições escolares. Dificilmente, podemos disciplinar uma pessoa em um campo aberto, onde Foucault (2004) chama de "instituição de sequestro". Os indivíduos são sequestrados para dentro da instituição, e então, são disciplinados. Após passar por esse processo de disciplinarização dentro da instituição, os sujeitos podem sair delas, visto que eles aprendem a exercer esses controles sobre si mesmos.

Assim, na escola, tudo o que é permitido é aquilo que não é proibido. Pensando na estética do pensamento de Certeau (1998), o melhor a ser feito é obedecer e, se possível, transgredir longe dos olhos dos professores, funcionários da escola e, até mesmo, das câmeras instaladas nos seus corredores. Os estudantes são sujeitos com subjetividade, que refletem sobre si mesmos, o outro, as coisas e o mundo. Diante da condição que a escola os obriga a estar, eles têm uma posição subjetiva perante isso e pode ter uma posição de atitude sobre tal situação, ou seja, o que o aluno como sujeito subjetivo faz com o que a escola os obriga a fazer. Como as crianças e adolescentes conseguem transgredir ou contribuir com esse disciplinamento? Seria isso possível? A posição subjetiva é a forma como o aluno processa a informação na sua idiossincrasia.

Fundamentados em Michel de Certeau, procuraremos entender o que os alunos usam de táticas, ou seja, bricolagens que os ajudam a sobreviver no ambiente escolar, embutido de normas. Eles não deixam de ser ou se comportar como querem, mas sabem que podem usar de táticas e conseguir conviver com as normas que são impostas e o que pode ser feito para que possa tirar "proveito" de alguma forma das situações que lhes foram atribuídas e que são favoráveis às bricolagens.

Desta forma, este trabalho tem o objetivo de compreender o uso da bricolagem por estudantes adolescentes de duas escolas públicas do interior do Estado de Sergipe como forma de resistência sobre o controle dos seus corpos instituídos no seu dia a dia e pela escola. Tentamos discutir e analisar os dados à luz de Michel de Certeau com base nos conceitos de táticas e estratégias, destacando as táticas, que são possíveis práticas que os estudantes 
adotam para se desviar das lógicas da escola que os disciplinam e tentar regular seus corpos.

Para melhor entendimento sobre estratégias e táticas em Michel Certeau, de forma breve e inteligível, segue o próximo tópico.

\section{Noções de estratégias e táticas}

O intelectual e historiador Michel de Certeau (1998) discute dois conceitos fundamentais na obra "A Invenção do Cotidiano: artes de fazer", que são os conceitos sobre estratégia e conceito de tática. Trataremos da estratégia e tática, neste momento, como conceito de interesse para reflexão sobre o tema elencado neste artigo.

Concernente à estratégia, Certeau (1998) obedece aos conceitos profícuo e contemporâneo, considerando-a um modo ou forma como o poder opera para dominar os fracos, além de apresentar o conceito de tática, que são as capacidades criativas, sutis, desviantes e sagazes que os estudantes adolescentes, ou melhor, os sujeitos, têm para confrontar a lógica do forte, da

118 autoridade, do dominante, ou seja, aqui, da escola e todo o seu sistema, também conceituada como bricolagem.

A estratégia está completamente ligada e associada à ideia de autoridade. Seja esta autoridade uma instituição, uma entidade comercial ou, até mesmo, um grupo de indivíduos agindo dentro de uma lógica que se reconheça a ordem ou status dominante da qual essa faz (CERTEAU, 1998). No nosso contexto, a estratégia está ligada, intimamente, à escola.

A estratégia pode se manifestar, fisicamente, por seus ambientes de operação ou configurando leis, normas, linguagem, modo de falar e agir. $\bigcirc$ que se espera da estratégia, também, é uma operação de custo considerável, visto que traz rentabilidade; em outras palavras, economia ou feedback positivo do que se deseja alcançar (CERTEAU, 1998). Nessa perspectiva, fazemos referência aqui à escola, que funciona sob uma lógica de controle e reprodução de corpos disciplinados, padronizados e dóceis. É justamente, nesse conceito de estratégia, que se sustenta a lógica da escola.

A estratégia, pela definição de Certeau (1998), além de estar associada à ideia de autoridade e a uma operação de rentabilidade considerável, deve ter uma base ou estrutura sólida para que não venha a se desestruturar 
com facilidade ou se reagrupar facilmente, pois ela possui um modelo próprio da sua instituição, órgão ou grupo. Nessa perspectiva, a escola criou um modelo institucionalizado de ensino que reprime e é adotado como modelo hegemônico difícil de ser desestruturado e fragmentado. Esse modelo ultrapassa séculos na educação.

Já a tática, para Certeau (1998), funciona de modo completamente diferente. Sem ter posses dos recursos dedicados, uma tática consegue ser ágil, flexível e desviante, se for comparada com a estratégia. Toda tática se baseia numa improvisação e não depende de um fundo próprio. Ao contrário disso, ela depende de uma economia dos presentes e não tem um caráter dominador. A tática, neste contexto do artigo, está ligada, intimamente, às bricolagens que os alunos adotam como desviantes das estratégias, impostas pelo sistema escolar, de normatização, rigor e disciplina.

Desta forma, Certeau (1 998) nos mostra a atenção e a percepção de que a tática pode ser manifestada de forma sutil e imperceptível dentro da própria tomada de estratégia da escola, considerada um "furo" nesse processo de disciplinamento do corpo.

Nessa configuração, a bricolagem é uma ferramenta de resistência inserida numa lógica simbólica dos alunos como subversão ao disciplinamento da escola diante de seus corpos. Quanto mais sutil e imperceptível à escola e aos professores, mais eficiente sua finalidade: desviar-se, fugir à regra, resistir aos disciplinamentos que thes são impostos, desviar e praticar ações com objetivo de benefício próprio ou coletivo no cotidiano escolar (CERTEAU, 1998).

Destarte, a tática ou bricolagem não é permanente ou fixa; ela muda de acordo com situações e espaços onde os sujeitos se encontram (CERTEAU, 1998). No contexto deste artigo, ela possui uma potência de levar o estudante adolescente a se beneficiar de situações corriqueiras tanto do cotidiano escolar quanto do familiar que thes são impostas.

\section{O corpo do estudante adolescente na escola}

A adolescência é uma transição entre a infância e a fase adulta. Essa fase que começa entre os 12 e 13 anos de idade pode variar entre os meninos e as meninas. É aqui que a antiga criança e o quase adulto se encontra na fase genital do desenvolvimento psicossexual ${ }^{1}$. $\bigcirc$ estudante adolescente 
começa a descobrir a sua sexualidade e, por meio desse processo de desenvolvimento psicossexual, de experiências sexuais e correlativamente, começa a (re)conhecer seu corpo (BEE, 1997; D'ANDREA, 1996; TALAMONI, 2007). A adolescência termina quando começa a maturidade ou idade adulta, por volta dos 20 anos mais ou menos.

É nessa fase, também, que o corpo do adolescente sofre alteração radical devido a liberações de hormônios na corrente sanguínea pelas glândulas endócrinas. Meninas e meninos começam a ter as alterações e diferenças sexuais secundárias dos seus corpos. As estudantes adolescentes têm a menarca, os seios crescem, nascem pelos, os quadris se alargam, o útero e os ovários se desenvolvem junto aos seus órgãos genitais; ocorre também o estirão do crescimento² (BEE, 1997; D'ANDREA, 1996).

Nos estudantes adolescentes, com a liberação de hormônio masculino, testosterona, os músculos crescem, hipertrofiam e pelos nascem em grandes proporções pelo corpo ${ }^{3}$. Pênis e testículos crescem e passam a ter a pele levemente escurecida. $\bigcirc$ corpo cresce de forma desproporcional ao corpo que outrora era de uma criança, a voz engrossa e há uma adaptação ao novo corpo que parece ainda não ser do adolescente. Começam as poluções noturnas, a masturbação e as curiosidades sexuais. Os meninos, geralmente, se voltam para a prática de esportes e gostam de exibir seus corpos quando percebem que chamam a atenção de outrem. Outros não se conformam com o seu corpo por sua desproporção de esquema corporal, causando uma distorção de sua autoimagem em comparação ao corpo do seu colega, pois essas alterações morfológicas do corpo são muito relativas de um adolescente para outro e dependem da sua carga genética (BEE, 1997; D'ANDREA 1996).

Os (as) estudantes, a partir das transformações corporais que ocorrem na adolescência, sofrem com fatores negativos, deixando-os com a autoestima baixa. Entre os fatores, está a acne ou "espinha", inimiga mais temida pelos adolescentes, pois podem deixar marcas no rosto para o resto da vida (TALAMONI, 2007).

Nas meninas, as transformações são mais rápidas e radicais, enquanto, nos meninos, são mais gradativas. Aumentam-se o peso, o tamanho corporal, modificam-se o humor e a personalidade, permanecendo em processo de desenvolvimento até a maturidade (BEE, 1997; D'ANDREA, 1996). 
Essa fase termina quando começa a maturidade ou idade adulta, por volta dos 20 ou mais.

É nessa fase da vida que a escola merece dar a devida atenção e assistência aos estudantes, pois se torna um momento em que suas personalidades ainda estão em formação. Concomitante, a personalidade do sujeito está intimamente ligada ao desenvolvimento e transformações físicas e psicológicas, pois "[...] as primeiras motivações e ansiedades do ser humano estão ligadas aos processos fisiológicos" (TALAMONI, 2007, p. 25). Portanto esses aspectos fisiológicos estão diretamente vinculados ao desenvolvimento físico e da personalidade (D'ANDREA, 1996). Então, o desenvolvimento do corpo, como se entende, é importante no desenvolvimento da personalidade e da identidade do sujeito, desde a sua infância até a maturidade.

Se a escola disciplina e nega o corpo do aluno e as transformações que thes ocorre, nega seu desenvolvimento e formação enquanto pessoa e cidadão. Dessa forma, é necessário explorar o que os alunos fazem e sabem com e sobre seu corpo no contexto da escola e do seu cotidiano.

\section{Etapas da coleta de dados}

Para melhor compreensão de como ocorreram as entrevistas com os estudantes adolescentes desta pesquisa, no quadro 1 há uma abreviação com a letra "A" (Entrevista de Grupo) e um número em seguida referente ao aluno. Esse número corresponde ao número do aluno entrevistado, do primeiro ao vigésimo primeiro (número total de alunos que participaram das discussões das Entrevistas de Grupo das duas escolas), sendo que os alunos de A1 ao A7, correspondem ao grupo da turma 1, da escola 1; do A8 ao A 15, correspondem ao da turma 2, da escola 2; e do A 16 ao A2 1, correspondem aos alunos da turma 3, da escola 2. Em suma, participaram das Entrevistas de Grupo sete alunos da (turma 1, escola 1) e quatorze alunos das (turmas 2 e 3, escola 2). 
O que fazer com o que a escola faz com meu corpo? Táticas de estudantes à luz de Michel de Certeau

Quadro 1

Entrevistas de Grupo

\begin{tabular}{|c|c|c|}
\hline \multicolumn{3}{|c|}{ Grupos } \\
\hline Turma 1-escola 1 & Turma 2-escola 2 & Turma 3-escola 2 \\
\hline $\mathrm{A} 1$ & $\mathrm{~A} 8$ & $\mathrm{~A} 16$ \\
\hline $\mathrm{A} 2$ & $\mathrm{~A} 9$ & $\mathrm{~A} 17$ \\
\hline $\mathrm{A} 3$ & $\mathrm{~A} 10$ & $\mathrm{~A} 18$ \\
\hline $\mathrm{A} 4$ & $\mathrm{~A} 11$ & $\mathrm{~A} 19$ \\
\hline $\mathrm{A} 5$ & $\mathrm{~A} 12$ & $\mathrm{~A} 20$ \\
\hline $\mathrm{A} 6$ & $\mathrm{~A} 13$ & $\mathrm{~A} 21$ \\
\hline $\mathrm{A} 7$ & $\mathrm{~A} 14$ & - \\
\hline- & $\mathrm{A} 15$ & - \\
\hline
\end{tabular}

Fonte: elaborado pelos autores.

\section{Entrevistas de Grupo com os alunos}

Foram feitas as entrevistas com vinte e um alunos das três turmas das duas escolas 1 e 2, com faixa etária de doze a dezesseis anos, mais especificamente estudantes do oitavo ano. As Entrevistas tiveram média de sete alunos, uma média dentro dos padrões dessa técnica (FLICK, 2009). Foi feito, apenas, um encontro com cada grupo/turma, suficiente para a discussão de temas pertinentes à questão de pesquisa, havendo uma duração média de uma hora e vinte minutos de discussão para cada grupo entrevistado. Foram utilizados dois gravadores de áudio para gravar as vozes dos alunos participantes; cada um se inscrevia para falar individualmente sobre as perguntas nas discussões. Os alunos se sentiram à vontade com os gravadores de áudio, e o ambiente de discussão se transformou num lugar de atmosfera natural; as discussões e insights foram e tornaram-se espontâneas (FLICK, 2009). 


\section{Análise e discussão}

Na entrevista, foi elaborada uma pergunta para roteiro da discussão do grupo de estudantes. Ela foi focada na questão de entender como os alunos atribuem o controle do cotidiano a partir da consciência do corpo, discutir o que eles aprendem na escola, se levam o que aprenderam na escola para seu cotidiano a partir da sua consciência de corpo. Foi uma temática pensada no objetivo do presente artigo. A questão norteadora da discussão foi: Você consegue controlar seu corpo? Com base nos dados obtidos e nas leituras sobre eles, conseguimos categorizá-los em sete temas que iremos descrevê-los, a seguir, para compreendê-los de forma sintética, inteligível e, posteriormente, apoiarmos na análise:

\section{Quadro 2}

Categorias temáticas

\begin{tabular}{|c|c|c|}
\hline Categorias & Estudantes Adolescentes & $\%$ \\
\hline $\begin{array}{l}\text { Conseguir controlar ou não as } \\
\text { necessidades fisiológicas: es- } \\
\text { fíncteres, a fome, a sede e o } \\
\text { sono. }\end{array}$ & $\begin{array}{l}\text { A12;A13; A15; A9; Al6; } \\
\text { A19, A5;A1;A6; A10;A17; } \\
\text { A21;A18;A2;A18;A4. }\end{array}$ & $76,19 \%$ \\
\hline $\begin{array}{l}\text { Controlar ou não a vontade de } \\
\text { falar ou bagunçar na sala de } \\
\text { aula }\end{array}$ & $\begin{array}{l}\text { A 12;A1 1;A15;A16;A20; } \\
\text { A21;A1;A6. }\end{array}$ & $38,09 \%$ \\
\hline $\begin{array}{l}\text { Controlar ou não a preguiça de } \\
\text { fazer as atividades diárias }\end{array}$ & $\begin{array}{l}\text { A12; A10;A14; A8; A16; } \\
\text { A21;A7; A5; A6; A4. }\end{array}$ & $47,61 \%$ \\
\hline $\begin{array}{l}\text { Não ter domínio sobre os } \\
\text { sonhos }\end{array}$ & $\begin{array}{l}\text { A12; A13; A15; A9; Al4; } \\
\text { A8;A1;A4. }\end{array}$ & $38,09 \%$ \\
\hline $\begin{array}{l}\text { Controlar ou não atitudes do } \\
\text { dia a dia }\end{array}$ & $\begin{array}{l}\mathrm{A} 13 ; \mathrm{A} 11 ; \mathrm{A} 9 ; \mathrm{A} 14 ; \mathrm{A} 8 ; \mathrm{A} 3 ; \\
\mathrm{A} 4 ; \mathrm{A} 1 ; \mathrm{A} 6 .\end{array}$ & $42,85 \%$ \\
\hline Desejos sexuais ou paixão & $\mathrm{Al6} ; \mathrm{A} 20 ; \mathrm{A} 19 ; \mathrm{Al} ; \mathrm{A4}$. & $23,80 \%$ \\
\hline Tensão pré-menstrual (tpm) e dor & A17; A19. & $9,52 \%$ \\
\hline
\end{tabular}

Fonte: elaborado pelos autores. 


\section{Conseguir controlar ou não as necessidades fisiológicas: esfíncteres, a fome, a sede e o sono}

Nessa categoria, os alunos falam sobre o controle de alguns aspectos fisiológicos do seu corpo como urinar ou defecar e faz comparação entre o homem X mulher. Controlar ou não os esfíncteres, a fome, a sede ou o sono:

"Eu controlo facilmente o xixi. Eu dormindo num sonho bom, dá preguiça de ir e eu controlo" (A12, 2016); "Acho que as mulheres, têm a possibilidade mais de segurar o xixi, porque acho que a uretra da mulher é maior e a do homem, menos. Eu aprendi isso nas aulas de ciências" (A13, 2016)4; "Eu controlo o xixi e outras coisas fisiológicas. Às vezes, as mulheres não podem controlar, porque estão "naqueles dias", menstruação" (A 15, 2016); "Eu controlo o xixi" $(\mathrm{A9}, 2016) ;$ " [...] mas também tipo se for uma vontade de urinar se for fraca eu consigo, mas se for forte, não! Ou mesmo uma dor de barriga a agente não consegue controlar" (A16, 2016); "Mas tem outras coisas do corpo que a gente não pode controlar: dor de barriga, dores musculares, o sono nem tanto" (A 19, 2016).

Os alunos relatam que conseguem controlar alguns esfíncteres como urinar, se a vontade não fosse muito forte ou se não for muito o tempo de espera em urinar, pois a bexiga tem um limite de armazenamento. Já sobre os esfíncteres de defecar, como dor de barriga, eles não controlam e citam, também, as dores musculares que são difíceis de controlar, não obstante, existem analgésicos e relaxantes musculares que aliviam a tensão e a dor. Utilizar analgésicos, relaxante muscular e controlar esfíncteres são táticas utilizadas pelos alunos como forma de burlar e controlar algumas sensações fisiológicas do seu corpo. Fazem esse tipo de ação quando se encontram em locais não adequados ou incertos para suas necessidades fisiológicas.

Podemos verificar que, na fase anal da criança, através da explicação de desenvolvimento de Freud, ela começa a ter controle muscular, e, por meio da sua organização psicomotora, ela começa a falar, andar e pode ter controle dos seus esfíncteres como urinar e defecar (TALAMONI, 2007). Assim, podemos verificar que os estudantes adolescentes do nosso trabalho têm controle sobre seus esfíncteres, configurando bricolagem diante de uma questão biológica do corpo. 
Acerca de ter consciência do seu corpo para ter controle sobre ele, Talamoni referencia que:

A criança, ao ter uma maior consciência de seu corpo bem como maior controle sobre ele, desenvolve o sentimento de que as coisas (que seu corpo produz) e os comportamentos (que seu corpo realiza voluntariamente) são seus, podendo ser 'ofertados' ou não. Percebe que a comunicação que é capaz de estabelecer com o mundo através de seu corpo, é algo que depende de sua vontade, e não mais apenas de sua necessidade (TALAMONI, 2007, p. 28-29).

Dessa forma, algumas sensações e necessidades fisiológicas podem ser controladas consciente e voluntariamente pelos alunos quando estão, na adolescência, pois já é uma fase de maturação maior que fica entre a infância e a idade adulta.

Igualmente, pode acontecer com outras necessidades fisiológicas como sono, fome e sede: "Mas tipo o sono eu consigo, mas quando estou bem cansado não consigo não!" (A16, 2016); "Eu não consigo controlaro sonho" (A 17); "As vezes consigo controlar o sono, ando um pouco, converso, saio da sala" (A18, 2016); "Eu consigo controlar meu sono" (A6, 2016); "Sim! Controlo! Consigo controlar a sede" (A13, 2016); "As vezes não consigo controlar a fome" (A10, 2016); "Eu não consigo controlar nem a fome e nem a sede [... a alguns a gente não consegue controlar os desejos do dia a dia como a fome" (A2 1, 2016); "Eu não consigo controlar a fome e nem a sede, pois não tem como. Em casa vou comer alguma coisa, nas escola peço para sair" (A 18, 2016); "Em alguns casos sim e em outros não!" (A2, 2016).

Controlar ou não fome, sede, sono, nos discursos transcritos de alguns estudantes, mostra que eles podem e têm controle sobre suas vontades, como, por exemplo, não comer muito chocolate e comer somente o suficiente, saber que beber água é importante para manter o corpo saudável e hidratado e que o sono se torna indispensável para repor as energias e o corpo entrar em descanso. Conhecendo seu corpo e sabendo das suas necessidades, os estudantes desse trabalho têm ciência do que é supérfluo para tal momento e o que é necessário. Como por exemplo: ter sede e não beber, pois sabe que quando estamos com sede nosso corpo está com necessidade de se hidratar. Quando está com sono, o corpo tem necessidade de recuperar energia e disposição. 
E quando se está com fome, há precisão de se nutrir para acumular energia e realizar determinadas tarefas.

Sabendo o que seu corpo necessita, conhecendo-o na sua totalidade, tendo consciência dos seus sentimentos, os alunos sabem o que deve ou não ser controlado pelo seu corpo conscientemente. Os alunos, por exemplo, sabem que precisam de água para se hidratar e apelam à tática, quando pede para sair da sala de aula, ir fazer xixi ou ir ao banheiro, conversar, andar, pois seria uma maneira de atender às suas necessidades fisiológicas e tentar fugir de uma aula que não tem muito sentido para o aluno.

\section{Controlar ou não a vontade de falar ou bagunçar na sala de aula}

Nesta categoria, destacamos algumas atitudes dos alunos na sala de aula de controlar a vontade ou atitude de bagunçar em sala de aula. Alguns relatam que conseguem controlar a vontade de bagunçar em sala de aula quando está em algazarra e outros confessam que quando a algazarra começa, não tem como não participar e também entram na bagunça. Esse tipo

126 de atitude faz lembrar o poder da indução que os alunos têm de praticar ou imitar atitudes dos outros sujeitos, geralmente quando são crianças.

Podemos verificar sobre essa imitação dos estudantes na teoria Psicanalítica de Freud aludida por Talamoni:

ego é antes de tudo, um ego corporal [...] aponta para a importância da identificação e da imitação, importantes recursos utilizados pelo bebê para o domínio do próprio corpo no estabelecimento de suas relações. Ou seja, é imitando a postura e outros "hábitos" corporais do adulto, que o bebê busca se comunicar com ele. Ele se apropria de seu próprio corpo, e toma conhecimento de seu corpo, através do corpo do outro (TALAMONI, 2007. p. 28).

Pela definição de Tática em Certeau (1998) bagunçar ou apoiar uma bagunça na sala de aula é uma forma de bricolagem, uma atitude que se desvia da norma, estratégia da escola ou do professor, de que deve se comportar, ficar sentado na cadeia e não fazer bagunça durante as aulas.

Portanto, verificamos, nos discursos a seguir, que os alunos tendem a imitar seu colega ao bagunçar, enquanto outros não entram na algazarra: "Eu 
não consigo controlar quando os colegas estão bagunçando na sala" IA12, $2016)$; "Em algumas situações de bagunça na sala, eu consigo controlar sim" (A1 1, 2016); "As vezes não! Eu não consigo controlar bagunça na sala de aula. Bagunço também!" (A15, 2016); "Também tem as vezes na sala de aula que eu quero prestar atenção no que o professor está falando e os colegas bagunçam, me dá vontade de bagunçar também, mas isso eu controlo, só gosto e ver os outros bagunçando, mas não bagunço não!" (A16, 2016); "Tipo, bagunçar na sala de aula quando ver outro colega bagunçando é uma ansiedade que dá. Eu não consigo controlar às vezes" (A20, 2016); "Quando uma colega bagunça na sala eu não consigo me controlar em ficar quieta e bagunço também" (A1, 2016).

Não bagunçar, mas apoiar a bagunça é uma forma indireta de participar dela e se safar de repreensões ou castigos posteriores, como é o caso do aluno A16 (2016) que usa da tática de não bagunçar junto aos seus colegas, mas gostar de vê-los bagunçando na sala de aula.

A bagunça não acontece somente pelo fato de indução porque o outro colega está bagunçando, mas também quando a aula está "chata" e o assunto não está sendo interessante. Podemos obter informações em diária de campo no qual os alunos falam que geralmente não bagunçam nas aulas de ciências, pois há coisas interessantes, mas bagunçam em outras aulas e citam como exemplo: as aulas de inglês e também matemática que, às vezes, têm assuntos "chatos" e que não vale a pena aprender, pois, segundo relatos, não servem para nada.

Em face do exposto, percebemos que o aluno tem controle sobre o corpo e suas atitudes, mas não tem interesse por algumas aulas que não têm sentido para eles e, como resultado, surge a algazarra como forma inconsciente ou consciente de protesto, na qual alguns estudantes participam, ativamente, e outros não. Dessa forma, algumas aulas não despertam no aluno o desejo de saber tal assunto tampouco a mobilização intelectual para aprendê-lo. Devemos salientar, então, a relevância de entender e entrar na lógica simbólica do aluno e também de atribuir importância às experiências e às concepções prévias que eles trazem para sala de aula (CHARLOT, 2000; 2005; CARVALHO, 1992).

Nesse sentido, o professor tem, como desafio, mediar os recursos, necessários para que os alunos possam se envolver, entrelaçar, se colocar à 
disposição "de", de aprender, perguntar, questionar e de ser entendido na sala de aula, por meio de instrumentos didáticos, capazes de aproximar a sua fala às falas dos alunos. Assim, construir um espaço de diálogo e de comprometimento é convidativo, para que os alunos possam se interessar por um conjunto de saberes que ainda não possuem. Ou então, usar da bricolagem de bagunçar ou estimular que outros façam algazarras na sala de aula.

\section{Controlar ou não a preguiça de fazer as atividades diárias}

Nessa categoria, destacamos se os estudantes conseguem fazer as suas atividades diárias ou têm preguiça em fazê-las ou ainda se conseguem ter controle sobre a preguiça de não querer fazer nada. Se conseguem fazer as atividades escolares de casa solicitadas pelo professor e, até mesmo, as atividades domésticas, como ajudar os pais em casa ou em algum trabalho, quando necessário. Quais são suas ações para bricolagem da preguiça?

Fazendo adendo à preguiça, para Charlot (2000, p. 52), o ser humano é inconcluso "[...] o homem não é, deve tornar-se o que deve ser; 128 para tal, deve ser educado por aqueles que suprem sua fraqueza inicial e deve educar-se". Portanto, a preguiça é aprendida, aprendemos ser preguiçosos. fato de ter preguiça, ou não, de fazer suas atividades diárias é uma prática que o sujeito aprende e não nasceu com ela. Deste modo, nascemos com a obrigação de aprender sobre algo ou sobre alguma coisa, e com a plasticidade de aprender várias coisas, até mesmo a ser preguiço e ter controle sobre a preguiça, fazendo uso de táticas.

Nas discussões do grupo de entrevistas, os alunos admitem ter preguiça com as atividades que o professor passa para ser feita em casa, bem como com as atividades domésticas; enquanto, outros confirmam não ter preguiça de fazer as suas atividades e conseguem controlar a vontade de não fazer nada, de ficar no ócio: "Eu faço as atividades diárias de dentro de casa, não tenho preguiça!" (A10, 2016); "Eu faço as atividades de casa porque sou forçado a fazer. Já fazemos muitas coisas na escola e ainda ter que fazer em casa?" (A8, 2016); "Quando minha mãe manda fazer alguma coisa em casa, eu vou!" (A16, 2016); "Assim eu tenho preguiça de estudar um pouco, mas consigo controlar um pouco, até os afazeres de casa. Eu consigo controlar tranquilamente" (A21, 2016); "Eu não consigo controlar a preguiça de estudar 
e fazer as coisas de casa" (A7, 2016); "[...] também eu tenho mais preguiça de estudar e fazer as coisas do dia a dia do que o controle dela" (A5, 2016); "Eu não consigo controlar a preguiça para estudar, mas para fazer as atividades diárias de casa eu não tenho preguiça não, eu controlo" (A6, 2016); "E eu consigo controlar a preguiça em estudar, em tudo. Quando eu digo que quero fazer eu vou lá, faço e estudo, eu acho que tenho mais controle" (A4, 2016).

O aluno A8 (2016) relata que já faz muitas atividades na escola e não faz as atividades da escola em casa. Existe uma lógica simbólica do aluno, de que as coisas da escola ficam na escola e as de casa ficam em casa. Essa é uma forma de justificar a sua preguiça e, também, uma prática desviante das normas que thes são atribuídas.

Assim, parafraseando Charlot (2000), estamos predispostos a nos tornar, não somos, por isso aprendemos a ter preguiça em fazer as atividades do dia a dia. No que se refere à preguiça ou sua fálta, o relało do aluno Al6 (2016) é bastante pertinente: "E eu gosto também de estudar, não tenho preguiça. Meu pai e minha mãe não tiveram estudo aí quando eu tenho vontade, eu chego e vou lá estudar, mas eles não me incentivam não". O aluno pode até não ter incentivo dos pais para estudar, e sabe que eles não tiveram "estudo", e isso se tornou um estopim, um divisor de águas para que ele continue a estudar e não fique na mesma posição dos pais dele, "sem estudo".

Em relação ao comentário supracitado sobre a fala do estudante A16 (2016), Charlot (2005) nos relembra que muitos alunos vão à escola para não ter o mesmo destino de seus pais; vão à escola para ganhar o diploma e ter um emprego melhor que o dos seus pais no futuro. Ter um emprego melhor para garantir um maior conforto se comparado com o que os seus pais thes oferecem hoje. O estudante considera a escola uma tática para mudança de vida, fazendo valer da sua posição social subjetiva como fonte mobilizadora e de bricolagem para êxito na escola e possivelmente na vida.

Na análise desse tópico do trabalho, verificamos que os estudantes sustentam, na preguiça, uma tática para não fazer as atividades diárias, solicitadas pelo professor, assim como também aprendem a ter controle passando a desenvolver outras atividades que não as da escola, mas a da sua própria casa. Não obstante, o estudante (A16, 2016), ao afirmar não ter preguiça, deixa explícito que, se estudar, passar de ano e ganhar um diploma, terá 
garantia de um emprego e de uma vida melhor que a dos seus pais, ou seja, ele consegue entrar numa lógica simbólica que configura a bricolagem.

\section{Não ter domínio sobre os sonhos}

Podemos ter controle sobre o nosso corpo de forma consciente, mas não nos sonhos, que faz parte da inconsciência da nossa mente. Os sonhos fazem parte dos nossos impulsos inconscientes assim como "[...] os impulsos, sexuais e agressivos, são aspectos instintivos de nossa vida mental, a partir dos quais se dá o desenvolvimento e funcionamento do aparelho psíquico. O ld, por sua vez, compreende as representações psíquicas dos impulsos" (TALAMONI, 2007, p. 26). Portanto, os sonhos estão nos impulsos do ld e não se tem controle sobre eles, visto que há aspectos instintivos, os quais não se podem controlar, conscientemente, já que estão inconscientes.

Os alunos comentam sobre o sonambulismo, enquanto estão dormindo, de experiências que tiveram e reconhecem que não tem controle sobre eles, e até mesmo os mistérios do cérebro que faz sonhar, falar e andar durante os sonhos, enquanto estão dormindo: "Quando estou sonhando eu bato a cabeça na cama, eu caio. E o nosso corpo, quando a gente tá sonâmbulo, a gente no subconsciente tá fazendo as coisas" (A12, 2016); "Eu fiquei falando dormindo. É impressionante [...] tem alguma coisa a ver com as células do cérebro que desliga no sonâmbulo uma parte do cérebro fica ligada, a motora" $(A 13,2016)$. "Eu falo também durante o sonho a noite" (A15); "Consigo controlar os meus sonhos! [...] eu às vezes quando estou dormindo, quando estou cansado, eu falo" (A8, 2016); "Ah! E tem meus sonhos! Eu amo meus sonhos e não consigo controlar [...] quando sonho, faço as coisas que estou sonhando, tipo, sonâmbula" $(\mathrm{A} 1,2016)$; "E também não consigo controlar [...] meus sonhos" (A4); "À noite eu começo a falar. Bem assim foi comigo, eu estava na cama, eu estava com sede, aí tem aqueles copos da santa e tinha água e eu bebi, dormindo" (A9, 2016).

Destarte, apresentamos controle sobre aquilo que temos consciência do que estamos fazendo, o que não podemos fazer com os sonhos, controlá-los. Verificamos, nos discursos descritos, que não há táticas de controle dos estudantes sobre seu corpo quando estão dormindo, pois se encontram 
inconsciente e não podem existir táticas no alcance da inconsciência (CERTEAU, 1998).

\section{Controlar ou não atitudes do dia a dia}

Nessa categoria, os alunos referem-se a algumas atitudes e decisões que podem ser tomadas com o seu consentimento como, por exemplo: brigar, ir para a rua, querer ou não usar drogas, desejos, mexer no celular, tomar decisões sobre tal coisa, não conseguir controlar o nervosismo na hora de apresentar trabalhos na escola, coisas que fazem parte do cotidiano.

"Tipo, se tiver uma droga, se você não quiser cheirar, não vai!" (A 13, $2016)$; "Mais ou menos! Na hora da briga você faz sem pensar, bate e depois você se arrepende" (A9, 2016); "Não consigo controlar! Às vezes nem sempre é briga [... não consigo controlar. Mas um organismo é diferente do outro [...] eu não gosto de controlar nada não!" (A14, 2016); "Dependendo da situação que se coloca, eu posso controlar ou não" (A8, 2016); "As vezes não ... porque as atitudes as vezes a pessoa vai e pensa uma coisa e depois pensa direito e pode se arrepender e já é tarde" (A3, 2016); "Às vezes quando eu estou apresentando trabalhos da escola eu começo a ficar nervoso e me tremer e eu não controlo isso" (A4, 2016). "Eu não consigo controlar o meu corpo, desejos e atitudes. Das atitudes porque as vezes eu faço coisas de cabeça quente e eu solto o que não deve" (A1, 2016). "Não controlo! [...] minhas atitudes" (A6, 2016).

Percebemos que a maioria dos alunos não consegue controlar suas atitudes, desejos, raiva e começa a partir para a briga, o nervosismo ao apresentar trabalhos escolares, e, às vezes, quando não controla esse tipo de atitude como brigar ou discutir com alguém, arrepende-se, mas percebe que já é tarde demais. A maioria age por impulso, principalmente na hora da raiva ou quando fala alguma coisa para alguém. Os alunos não conseguem controlar impulsos de raiva e, na maioria das vezes, brigam, ou seja, burlam as regras da escola que não apoia toda e qualquer violência para com o seu colega ou outrem. Dessa forma, a raiva é um sentimento que pode culminar num comportamento ou ação inesperada do estudante, configurando uma tática, pois pode romper com as normas das políticas de ordem e paz na escola. 
Nas discussões dos grupos, sobressai a fala do aluno A1 1 (2016) "Eu acho que eu consigo controlar o que eu quero fazer. Se eu quero ir pra rua eu controlo. Se eu quero usar droga, se eu não quero usar droga, eu controlo [...] Tudo, no meu corpo, quem manda sou ev e mais ninguém!". O aluno reconhece que controla o seu corpo, ou seja, suas vontades ou desejos. Ademais, reconhece seu corpo sendo propriedade em que ele pode decidir o que quer $e$ o que não quer, o que deve ser feito e não pode ser feito, tudo depende dele, do seu corpo.

A fala do estudante aparenta que ele tem uma autonomia das suas decisões, na qual ele é o único responsável pelo que acontece de bom ou de ruim consigo mesmo e usa das suas experiências de corpo para controlar suas atitudes, desejos e decisões. Verificamos táticas conscientes dele diante de diversas situações referentes ao controle dos seus desejos, vontades, sentimentos, comportamento e atitudes cotidianas, ligadas ao corpo. Ao mesmo tempo, demonstra um disciplinamento diante de certas atitudes ou ações do dia a dia, um corpo docilizado (FOUCAULT, 2004).

No tocante ao aspecto educacional sobre controle e/ou consciência de corpo, parafraseando a Lei n 9.394/96 Lei de Diretrizes e Bases da 132 Educação Nacional, a escola pretende formar alunos autônomos, com visão e consciência crítica sobre assuntos que norteiam a sociedade, como drogas, sexualidade, cidadania. Formar alunos que se tornem cidadãos independentes, que tenham consciência de seus corpos não como um objeto que ocupa um local no espaço, mas como um corpo que age, faz, cria, tem atitudes conscientes e responsáveis diante de situações vivenciadas (BRASIL, 1996).

\section{Desejos sexuais ou paixão}

Nessa fase da adolescência, os estudantes estão com os hormônios gonadotróficos sendo liberados e, com essa explosão de hormônios, transformações surgem a cada momento e as descobertas de sensações nunca antes, nunca sentidas vêm à tona, tendo oportunidades de descobrir o que nunca foi falado, visto ou sentido. Consideramos importante salientar, aqui, os desejos sexuais dos alunos e paixões que podem acontecer nessa fase adolescente. Na adolescência, os alunos começam a se atrair ou não por pessoas, há 
modificação corporal, mental, emocional e sua sexualidade se aflora (BEE, 1997; D'ANDREA, 1996; TALAMONI, 2007).

Nessa categoria, fica em latência o assunto sexualidade, mas subentende que os alunos a ela se referiam, visto que é um assunto pouco falado ou conhecido e ainda traz um pouco de vergonha para os alunos adolescentes conversarem, abertamente, sobre tal, principalmente em suas casas, onde seus pais ainda não compreendem que estão numa fase de transição entre a infância e a idade adulta. Talamoni (2007) nos ajuda a compreender que todo ou qualquer assunto sobre sexualidade na adolescência, é camuflado no círculo familiar e, quando é comentado, geralmente, são as mães dos adolescentes que sanam suas dúvidas mediante a sua experiência empírica e não dão respostas científicas sobre o assunto exposto (TALAMONI, 2007).

Eis alguns comentários: "Tipo a paixão a gente não controla, quando você vê uma pessoa assim aí bate o desejo e você não consegue controlar [...] e eu também acho que consigo controlar algumas imaginações, eu penso o que quero" (A 16, 2016); "Eu acho que algumas emoções a gente consegue controlar às vezes dependendo da situação, mas algumas partes do corpo não, porque a gente às vezes não tem controle de tudo que acontece com a gente" (A20, 2016); "Depende! Porque você tem seus desejos você pode controlar, agora meu corpo, assim várias coisas eu não posso controlar e outras eu posso [...] beijar alguém a gente pode controlar" (A19, 2016); "Eu não consigo controlar o meu corpo, desejos e atitudes [...] os desejos é que eu tenho uns desejos alterados, desejos dos sentimentos" (A 1, 2016); "Não! Nem tudo eu consigo controlar porque não são de acordo comigo, são de acordo com meus órgãos" (A4, 2016).

A paixão e os desejos sexuais, nessa fase da vida, às vezes, se tornam difíceis de ser entendidos e controlados pelos estudantes adolescentes. Segundo Schuch (1998), em uma pesquisa feita entre estudantes universitários solteiros de Porto Alegre, no Rio Grande do Sul, verificou que, quando os universitários estão apaixonados, não controlam seus desejos avassaladores da paixão e do sexo, não conseguindo, às vezes, sequer usar camisinha no ato sexual, fazendo o uso de bricolagens perigosas que podem causar ônus aos estudantes.

Nessa fase, há prática quase constante da masturbação como forma de escape de seus desejos sexuais e curiosidades, mais frequentemente 
relatados pelos meninos (BEE, 1997; D'ANDREA, 1996), configurando um tipo de tática natural de escape. Os desejos e os sentimentos às vezes não são controlados, como descreve o aluno Al (2016) e também não conseguem controlar os seus órgãos, ou seja, seus desejos sexuais, como descreve também o aluno A4 (2016). Percebemos, então, que a única forma de bricolagem sobre os desejos sexuais e paixões dos estudantes adolescentes é a masturbação, a qual fica subentendida nos comentários dos alunos, mas claras diante das "caras" e "bocas" que fizeram durante a entrevista.

Dessa forma, os Parâmetros Curriculares Nacionais nos indicam que o aluno deve ser orientado nas aulas sobre sexualidade. Os estudantes têm o direito de ser orientados, tendo consciência sobre a adolescência e as transformações do corpo que ocorrem, nessa fase, conhecer sobre os órgãos sexuais masculinos e femininos, sobre o uso de métodos contraceptivos e o uso de preservativos para prevenção de DST e cuidados para com a saúde genital e física, tornando o aluno crítico e responsável pela saúde sexual presente ou futura (BRASIL, 1998).

Nesse sentido, colocar temas que transversalizam a adolescência à margem da escola, como propõe a escola sem partido, é negar aos adolescen-

134 tes o direito do autoconhecimento e do respeito às diferenças, à diversidade e do autorreconhecimento enquanto pessoa e identidade. $\bigcirc$ uso de bricolagem dos alunos diante de tais situações como aquelas propostas pela escola sem partido, seria solícito diante de normatizações.

\section{TPM e Dor}

A discussão ligada à menstruação, as dores musculares, as cólicas e a TPM fazem parte dessa categoria, pois os alunos referem ao que não conseguem controlar: "Eu acho que o que a gente não consegue controlar muito, as mulheres, é a TPM, quando a gente está no período da menstruação que a cólica é tão forte [...] ninguém consegue controlar. Não controlo a raiva, deve ser por causa dos hormônios" (A 17, 2016); "[...] dores musculares" (A 19, 2016).

assunto mais comentado no grupo de entrevista entre as meninas, diz respeito à menstruação e às suas reações secundárias como cólica e TPM, causando mal humor; é um tema sempre abordado quando se fala em corpo 
humano e, principalmente, quando fala de adolescência, não conseguindo enxergá-lo como assunto banal, pois traz lembranças de dor e nojo ao sangue pelas alunas adolescentes. Haveria um paliativo ou tática diante das cólicas, o analgésico, mas, como observamos, os alunos Al7 (2016) e A19 (2016) não conseguem controlá-las e o mau humor, causado pela menstruação, as deixam passivas diante do ciclo menstrual natural.

\section{Considerações finais}

Em face do exposto, concluímos que a tática ou bricolagem é uma arte de viver, sobretudo, diante das normatizações impostas por grupos sociais, instituições escolares e, até mesmo, perante as necessidades fisiológicas humanas. Consideradas e conceituadas como práticas desviantes, sem as quais os estudantes adolescentes não suportariam viver socialmente, as táticas configuram ações de relação, nas quais os alunos conseguem manter-se vinculados à instituição escolar, à família, aos amigos e a ter uma relação consigo mesmo diante da sua corporeidade.

Neste trabalho, a tática é conceituada e considerada uma possível forma de resistência dos estudantes diante das normas sobre o corpo e sobre o controle que a escola desloca diante do aluno visando configurar uma performance de bom comportamento nos espaços da escola, realizar as atividades de casa solicitadas pelos professores, de não fazer algazarra na sala de aula, de que a escola é um espaço de silêncio e obediência. A bricolagem serve, também, como forma de subversão e/ou resistência às atividades cotidianas, sobre desejos sexuais, sobre a raiva, necessidades fisiológicas, dores corporais, preguiça, menstruação e TPM.

As atitudes cotidianas dos estudantes são permeadas de ações nas quais podem usar de bricolagens como táticas de vivências dentro e fora do ambiente escolar. Com base na posição subjetiva dos estudantes adolescentes diante das estratégias da escola e das suas normas disciplinantes, a maioria se mostra desviante do que a escola objetiva, conscientemente, como controle através das normas.

Na aresta da estratégia, podemos considerar pelo que explicitamos, no entorno deste trabalho, que ela é abordada como ação ligada ao exercício de poder. No nosso contexto, o poder normatizador e de autoridade da escola 
diante dos estudantes adolescentes. Ademais, é uma estratégia social, construída socialmente e que tem poder sobre os corpos dos estudantes adolescentes numa escala que chega a discipliná-los diante de atitudes e ações cotidianas.

espectro de normatização e de controle dos corpos dos estudantes consegue ultrapassar os muros da escola, adentrando no vínculo familiar, de amizade, social e pessoal, alterando, assim, as suas formas de se relacionar com o mundo, com os outros e consigo mesmo.

\section{Notas}

1 Vale salientar que as fases psicossexuais ocorrem durante esse período da formação da personalidade do indivíduo. $\bigcirc$ sujeito pode não superar uma fase e passar pelas outras sem conseguir sair da anterior, o que poderá resultar em algum problema na sua personalidade futuramente.

2 Deve-se observar que, em algumas meninas, os seios se desenvolvem bem pouco, pelo menos aparentemente. Da mesma forma, algumas não apresentam desenvolvimento dos quadris nem de altura, ou seja, as transformações secundárias são muito relativas ao sujeito, pois depende da genética e fatores ambientais.

3 Vale salientar que as transformações secundárias são inerentes ao sujeito, visło que dependem da genética e fatores ambientais.

1364 Observação: $\bigcirc$ aluno se equivocou e retificamos, na discussão, que a uretra do homem era mais longa que a da mulher.

\section{Referências}

A 1. Entrevista gravada. Cumbe (Sergipe), 16 dez. 2016.

A2. Entrevista gravada. Cumbe (Sergipe), 16 dez. 2016.

A3. Entrevista gravada. Cumbe (Sergipe), 16 dez. 2016.

A4. Entrevista gravada. Cumbe (Sergipe), 16 dez. 2016.

A5. Entrevista gravada. Cumbe (Sergipe), 16 dez. 2016.

A6. Entrevista gravada. Cumbe (Sergipe), 16 dez. 2016.

A7. Entrevista gravada. Cumbe (Sergipe), 16 dez. 2016.

A8. Entrevista gravada. Cumbe (Sergipe), 16 dez. 2016.

A9. Entrevista gravada. Cumbe (Sergipe), 16 dez. 2016. 
A10. Entrevista gravada. Cumbe (Sergipe), 16 dez. 2016.

A 1 1. Entrevista gravada. Cumbe (Sergipe), 16 dez. 2016.

A12. Entrevista gravada. Cumbe (Sergipe), 16 dez. 2016.

A13. Entrevista gravada. Cumbe (Sergipe), 16 dez. 2016.

A 14. Entrevista gravada. Cumbe (Sergipe), 16 dez. 2016.

A15. Entrevista gravada. Cumbe (Sergipe), 16 dez. 2016.

A 16. Entrevista gravada. Cumbe (Sergipe), 16 dez. 2016.

A17. Entrevista gravada. Cumbe (Sergipe), 16 dez. 2016.

A 18. Entrevista gravada. Cumbe (Sergipe), 16 dez. 2016.

A 19. Entrevista gravada. Cumbe (Sergipe), 16 dez. 2016.

A20. Entrevista gravada. Cumbe (Sergipe), 16 dez. 2016.

A2 1. Entrevista gravada. Cumbe (Sergipe), 16 dez. 2016.

BEE, Helen. O ciclo vital. Porto Alegre: Artmed, 1997.

BRASIL. Lei n 9394, de 20 de dezembro de 1996. Estabelece as Diretrizes e Bases da Educação Nacional. Diário Oficial [da] União, Poder Executivo, Brasília, DF, 23 dez. 1996.

Parâmetros Curriculares Nacionais: temas transversais (quinta a oitava séries). Brasilia: MEC/SEF, 1998.

CARVAlHO, Ana Maria Pessoa de. Construção do conhecimento e ensino de Ciências. Em Aberto, Brasília, v. 1, n. 55, jul./set. 1992.

CERTEAU, Michel de. A invenção do cotidiano: artes de fazer. Tradução Ephraim Ferreira Alves. 3. ed. Petrópolis: Editora Vozes, 1998.

CHARLOT, Bernard. Da relação com o saber: elementos para uma teoria. Tradução Bruno Magne. Porto Alegre: Artmed, 2000.

Relação com o saber, formação dos professores e globalização: questões para a educação de hoje. Porto Alegre: Artmed, 2005.

Da relação com o saber às práticas educativas. São Paulo: Cortez, 2013. 
D'ANDREA, Flavio Fortes. Desenvolvimento da personalidade: enfoque psicodinâmico. 12. ed. Rio de Janeiro: Bertrand Brasil, 1996.

FLICK, Wue. Introdução à pesquisa qualitativa. 3. ed. Porło Alegre: Artmed, 2009.

FOUCAULT, Michel. Vigiar e punir: nascimento da prisão. Tradução Raquel Ramalhete. 29. ed. Petrópolis: Vozes, 2004

$\mathrm{SCHUCH}$, Patrice. AIDS e sexualidade entre universitários solteiros de Porto Alegre: um estudo antropológico. In: DUARTE, Luiz Fernando; LEAL, Ondina Fachel (Org.). Doença, sofrimento, perturbações: perspectivas entnográficas. Rio de Janeiro: Editora Fiocruz, 1998.

TALAMONI, Ana Carolina Biscalquine. Corpo, ciência e educação: representações do corpo junto a jovens estudantes e seus professores. 2007. 198f. Dissertação (Mestrado em Educação para a Ciência) - Programa de Pós-Graduação em Educação para a Ciência, Universidade Estadual Paulista "Júlio de Mesquita Filho", Bauru, 2007.

Prof. Ms. Eanes dos Santos Correia Universidade Federal de Sergipe

Doutorando do Programa de Pós-Graduação em Educação Grupo de Estudo e Pesquisa Educação e Contemporaneidade (EDUCON/UFS/ $\mathrm{CNPq}$ Grupo de Pesquisa em Ensino de Ciências (GPEC/UNESP/CNPq)

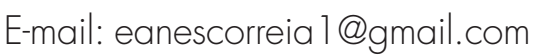

Profa. Dra. Veleida Anahi da Silva Universidade Federal de Sergipe Departamento de Educação

Programa de Pós-Graduação em Educação

Programa de Pós-Graduação em Ensino de Ciências Naturais e Matemática Coordenadora do Grupo de Estudo e Pesquisa Educação e Contemporaneidade (EDUCON/UFS/CNPq) E-mail:vcharloł@terra.com.br 
Doutorando Willdson Robson Silva do Nascimento Universidade Estadual Paulista "Júlio de Mesquita Filho" (Campus Bauru) Programa de Pós- Graduação em Educação para Ciência Grupo de Pesquisa em Ensino de Ciências e Inclusão Escolar (ENCINE/UNESP/ CNPq) Grupo de Estudo e Pesquisa Educação e Contemporaneidade (EDUCON/UFS/ $\mathrm{CNPq}$

E-mail:willdsonnascimento@gmail.com

Recebido 22 jun. 2018

Aceito 3 set. 2018 